\section{Whole-Genome-Amplification (WGA)}

\section{J. Arnemann}

Abteilung Molekulargenetik, Labor Dr. Wisplinghoff, Köln, Deutschland

\section{Synonym(e) WGA}

Englischer Begriff whole-genome amplification; WGA

Definition Whole-Genome-Amplification (WGA) ermöglicht eine massive Vervielfältigung kleinster Mengen DNA aus wenigen Zellen bis hin zu Einzelzellen zum Zweck der Genotypisierung und Sequenzierung.

Beschreibung Die Methode der Whole-Genome-Amplification beruht auf der Amplifikation geringster DNA-Mengen mittels ,random primer“ (Zufallsprimer), die über das Genom nach dem Zufallsprinzip verteilt binden und diese Abschnitte amplifizieren.

Über die vergangenen Jahre wurden mehrere Modifikationen diese Prinzips entwickelt, wie z. B. ,primer extension preamplification“ (PEP), bei der 15 bp-lange Zufallsprimer aus tausenden Kombinationsmöglichkeiten zunächst bei niedriger Temperatur $\left(37^{\circ} \mathrm{C}\right)$ an die DNA binden (,annealing"), die aber über die verschiedenen Amplifikationszyklen bis hin zu $55{ }^{\circ} \mathrm{C}$ erhöht wird. Nach Literaturangaben soll mit dieser Methode 96 \% des Genoms mindestens 1000-fach amplifiziert werden.

Eine Alternative ist „,degenerate oligonucleotide primedpolymerase chain reaction“ (DOP-PCR), bei der die eingesetzten Primer nur leicht degeneriert sind und nicht die hohe Zufallsverteilung zeigen. Auch hier werden zunächst Zyklen mit niedriger Annealing-Temperatur durchgeführt, um eine zunächst möglichst breite, unspezifische Amplifikation zu erzielen. Durch Erhöhung der Annealing-Temperatur wird im nächsten Schritt die Spezifität der Amplifikation erhöht. Als Ausgangsmaterial werden 15 pg beschrieben, die amplifizierte Menge sollte aber der PEP-Methode entsprechen. Beide Methoden, PEP und DOP-PCR, haben den großen Nachteil, dass relativ kurze Amplifikationsprodukte generiert werden, deren Einsatzmöglichkeiten eingeschränkt sind.

Eine aktuellere Alternative ist ,multiple displacement amplification" (MDA). Hierbei gibt es entscheidende Veränderungen. Zum einen wird statt Taq-DNA-Polymerase die phi29-DNA-Polymerase eingesetzt, zum anderen sind die Zufallsprimer modifiziert mit Phosphorothioat. Die Modifikation schützt die Primer vor einer Degradation durch die $3^{\prime}-5$ '-Proofreadingaktivität und erlaubt so eine Amplifikation von 100 Zyklen. Aufgrund der Proofreadingaktivität wird auch die Fehlerrate signifikant reduziert auf 3/1.000.000 Nukleotide pro Minute, während die Taq-DNA-Polymerase in den anderen Ansätzen eine publizierte Fehlerrate von 1/1000 Nukleotide pro Minute zeigt. Mittels dieser Technik kann ein komplettes Genom amplifiziert werden, eventuell sogar im Milligrammmaßstab.

Whole-Genome-Amplification (WGA) wird bevorzugt in den Bereichen Onkologie und Reproduktionsmedizin eingesetzt. Hier wird insbesondere im Bereich der $>$ Präimplantationsdiagnostik (PID) molekulare Diagnostik an Einzelzellen durchgeführt.

\section{Literatur}

Hosono S et al (2004) Unbiased whole-genome amplification directly from clinical samples. Genome Res 13:954-964 